\title{
Illusory Upward Self-Motion Results in a Decrease in Perceived Room Temperature
}

\author{
Takeharu Seno ${ }^{1,2,3}$, George H. Van Doorn ${ }^{4}$ \\ ${ }^{1}$ Institute for Advanced Study, Kyushu University, Fukuoka, Japan \\ ${ }^{2}$ Faculty of Design, Kyushu University, Fukuoka, Japan \\ ${ }^{3}$ Research Center for Applied Perceptual Science, Kyushu University, Fukuoka, Japan \\ ${ }^{4}$ School of Applied Media and Social Sciences, Monash University, Melbourne, Australia \\ Email: seno@design.kyushu-u.ac.jp, george.vandoorn@monash.edu
}

Received August 21 $1^{\text {st }}, 2013$; revised September $22^{\text {nd }}, 2013$; accepted October $23^{\text {rd }}, 2013$

Copyright (C) 2013 Takeharu Seno, George H. Van Doorn. This is an open access article distributed under the Creative Commons Attribution License, which permits unrestricted use, distribution, and reproduction in any medium, provided the original work is properly cited.

\begin{abstract}
Purpose: Stationary observers often experience illusory self-motion (vection) when they are exposed to large patterns of optic flow. The effect of different temperatures on the strength of vection was investigated. Method: Eleven participants were exposed to visual stimuli that induced illusory motion (up, down) in three room temperatures $\left(26^{\circ} \mathrm{C}-27^{\circ} \mathrm{C}, 21^{\circ} \mathrm{C}-22^{\circ} \mathrm{C}, 5^{\circ} \mathrm{C}-6^{\circ} \mathrm{C}\right)$. Participants rated (a) the vection magnitude, and (b) the room temperature (twice; before and after vection). Results: Upward vection was rated as stronger than downward vection in the $26^{\circ} \mathrm{C}-27^{\circ} \mathrm{C}$ temperature. In addition, after experiencing upward and downward vection, subjective ratings of room temperature decreased and increased, respectively, when the room temperature was $26^{\circ} \mathrm{C}-27^{\circ} \mathrm{C}$. This effect was not observed when the room was $5^{\circ} \mathrm{C}-6^{\circ} \mathrm{C}$. Conclusion: These results suggest that a cross modal association exists between the direction "up" and $26^{\circ} \mathrm{C}-27^{\circ} \mathrm{C}$ temperatures.
\end{abstract}

Keywords: Vection; Temperature; Vision; Illusory Self-Motion

\section{Introduction}

Exposure to a visual motion field that simulates the retinal optical flow generated by self-movement commonly causes the perception of the subjective movement of one's own body. This phenomenon is known as "vection" (Fischer \& Kornmuller, 1930). For example, when a stationary person observes a train beginning to move, they are likely to perceive that they are moving in the opposite direction to the motion of the train. This phenomenon is known as the "train illusion", and provides a good example of vection (e.g. Seno \& Fukuda, 2012). Some recent studies reported that vection can modulate aspects of perception and cognition, e.g. daydreaming (Miles, Karpinska, Lumsden, \& Macra, 2010), attention (Seno, Ito, \& Sunaga, 2011a), time perception (Seno, Ito, \& Sunaga, 2011b), perception of numbers (Seno, Taya, Ito, \& Sunaga, 2011), and visual illusions (Fukuda \& Seno, 2011; Fukuda \& Seno, 2012). Vection is also affected by personality traits such as narcissism (Seno, Yamada, \& Ihaya, 2011). In this study, we assessed for the first time whether vection can be modulated by temperature, or can have a modulating influence on perceived temperature.

Soto-Faraco, Spence and Kingstone (2004) suggested that a feature in one sensory modality can be associated with a feature in another sensory modality, i.e. a cross-modal correspondence. Although different sensory organs receive different inputs, interactions between sensory modalities occur after these inputs have been recoded at post-perceptual levels (Marks, 2004); recoding activates a representation that captures elements of each input that are common across modalities (Martino \& Marks,
2000). Consequently, reaction times (RTs) to a simultaneously presented high-pitched tone and a light coming from above might be shorter, for example, than RTs to a low-pitched tone and a light coming from above; the recoded inputs of the former pair share the post-perceptual format "high", whereas the later do not.

Similar to Mark's (2004) work, Seno, Ito, Sunaga, Hasuo, Nakajima and Ogawa (2011) recently proposed a consistency hypothesis that predicts that visually-induced self-motion will be enhanced when inputs from one (or more) of the non-visual senses are consistent with visual simulation. Consistent with the predictions of this hypothesis, somatosensory stimulation generated by adding air-flow to a stationary observer's face significantly $(p<.05)$ enhanced visually-simulated forward motion (Seno, Ogawa, Ito, \& Sunaga, 2011). In addition, vection has been facilitated by vibrations on the body and auditory cues that are consistent with visual rotation (Riecke, Schulte-Pelkum, Caniard, \& Bülthoff, 2005; Riecke, Feuereissen, \& Rieser, 2008). Crossmodal correspondence, or consistency, seems to be nonarbitrary and accumulated through repeated exposure to pairs of stimuli (Williams \& Bargh, 2008). As we go through life experiencing wind against our face, for example, it becomes paired with forward motion.

This idea can be applied to temperatures and spatial directions (up/down) which may be semantically associated in everyday language (e.g. "hot air rises"). If a correspondence exists between "hot" temperatures and "upward" direction (and vice versa for "cold" and "down") then vection may be influenced by temperature; specifically, upward vection would be stronger 
when the temperature of a room is hotter than usual, and vice versa for colder temperature. In addition, illusory change in room temperature may arise as a result of perceiving vection. Thus, we tested the following hypotheses:

$\mathrm{H} 1$ : In a $26^{\circ} \mathrm{C}-27^{\circ} \mathrm{C}$ room, upward vection will be stronger than illusory self-motion in other directions.

$\mathrm{H} 2$ : Subjective ratings of room temperature will be hotter after experiencing upward vection, and cooler after downward vection.

\section{Method}

\section{Participants}

Eleven volunteers (seven females) took part in the experiment. The participants had a mean age of 24.8 years $(\mathrm{SD}=3.7$ years). All participants had normal or corrected-to-normal vision and none of them reported visual or vestibular abnormalities. The experiments were pre-approved by the ethics committee of Kyushu University, and written informed consent was obtained from each subject prior to participating.

\section{Materials and Stimuli}

The up/down vection stimulus was a white vertical sinusoiddal grating whose luminance was horizontally modulated. Motion displays subtended a visual area of $72^{\circ}$ (horizontal) $\times 57^{\circ}$ (vertical) when viewed from $570 \mathrm{~mm}$ in front of a television screen. Upward/downward vection was induced by moving the grating (spatial frequency: .1 cycle/deg; mean luminance: 18 $\mathrm{cd} / \mathrm{m}^{2}$; Michelson contrast: $80 \%$ ) down/up, respectively, at a speed of $\sim 20 \mathrm{deg} / \mathrm{sec}$. We used virtually continuous motion in the minimum motion technique that was essentially the same as that used in Cavanagh, MacLeod and Anstis (1987). Each up/ down motion stimulus consisted of 13 images presented sequentially and repeatedly. The gratings moved in only one direction for the duration of each trial, which was fixed at $30 \mathrm{sec}$. There was also a static (i.e. control) grating condition.

The experiment was conducted in a $7 \mathrm{~m} \times 7 \mathrm{~m} \times 2.6 \mathrm{~m}$ darkened room. There were three room temperature conditions, i.e. normal $\left(21^{\circ} \mathrm{C}-22^{\circ} \mathrm{C}\right)$, hot $\left(26^{\circ} \mathrm{C}-27^{\circ} \mathrm{C}\right)$, and cold $\left(5^{\circ} \mathrm{C}-6^{\circ} \mathrm{C}\right)$. Room temperature was modulated and kept constant by the two air conditioners. Room temperature was certificated by the thermometer.

\section{Procedure}

Prior to the presentation of stimuli, participants were asked to sit down; they remained seated for the entire experiment. Before each stimulus combination was presented (e.g. $5^{\circ} \mathrm{C}-6^{\circ} \mathrm{C}$ temperature/upward grating pattern) participants were asked to estimate the room temperature to one decimal point (e.g. $23.5^{\circ} \mathrm{C}$ ). They were also instructed to press a button during each trial if/ when they experienced vection, and were to keep the button depressed for as long as the experience lasted. If vection ceased, or became ambiguous, they were to release the button. Duration and latency of vection were recorded as dependent variables. Latency was defined as the time interval between the onset of the visual stimulus and the time at which the participant pressed the button. Duration was calculated as the total time that the button was pressed until it was released.

Following the instructions a motion stimulus was presented. After the $30 \mathrm{sec}$ stimulus presentation period ended, and after participants released the button to signify that vection had ceased, participants rated the strength of vection by verbally stating a number from 0 (no vection) to 100 (very strong vection); the experimenter recorded this number on a piece of paper. Participants then estimated the room temperature again, and the difference between pre- and post-trial estimations was calculated.

There were two motion directions and three room temperature conditions. There were four trials per condition, and thus a total of 24 trials per participant. The presentation order of trials was randomized. Each temperature condition lasted approximately 20 mins. Thus the experiment had a total duration of approximately 60 mins for each participant. All conditions were interior-group design.

It is known that vection can be modulated by an experimenter's instructions or demands (Palmisano \& Chan, 2004). Thus, we carefully instructed the participants regarding their task without giving them any suggestion which may lead to a cognitive bias about the consistency hypothesis. Furthermore, several control conditions were included in an attempt to negate potential extraneous variables.

\section{Results}

A 3 (temperature: $21^{\circ} \mathrm{C}-22^{\circ} \mathrm{C}, 26^{\circ} \mathrm{C}-27^{\circ} \mathrm{C}, 5^{\circ} \mathrm{C}-6^{\circ} \mathrm{C}$ ) $\times 3$ (grating motion: upward, downward, static) repeated-measures ANOVA on subjective ratings of vection strength revealed a significant main effect of temperature $[\mathrm{F}(2,20)=21.62, p$ $\left.<.0001, \eta^{2}=.16\right]$. Vection was weaker in the $26^{\circ} \mathrm{C}-27^{\circ} \mathrm{C}$ condition than in the $21^{\circ} \mathrm{C}-22^{\circ} \mathrm{C}$ and $5^{\circ} \mathrm{C}-6^{\circ} \mathrm{C}$ cold conditions (see Figure 1). This is supported by the duration and latency data which were significantly shorter and longer, respectively, in the $26^{\circ} \mathrm{C}-27^{\circ} \mathrm{C}$ condition relative to the $21^{\circ} \mathrm{C}-22^{\circ} \mathrm{C}$ and $5^{\circ} \mathrm{C}$ $-6^{\circ} \mathrm{C}$ conditions [duration: $\mathrm{F}(2,20)=6.83, p=.005, \eta^{2}=.06$; latency: $\left.\mathrm{F}(2,20)=13.62, p=.0002, \eta^{2}=.21\right]$.

The main effect of the grating motion was significant [magnitude: $\mathrm{F}(2,20)=66.62, p<.0001, \eta^{2}=.16$; duration: $\mathrm{F}(2,20)=$ $86.29, p=.005, \eta^{2}=.70$; latency: $\mathrm{F}(2,20)=54.36, p<.0001, \eta^{2}$ $=.55]$. Bonferroni-corrected post-hoc tests revealed significant differences between the static grating and the others $(p<.05)$. Importantly, the direction of illusory self-motion experienced by each participant was consistent with previous research (e.g. Seno, Ito, \& Sunaga, 2009).

The interaction between temperature and grating motion was significant [magnitude: $\mathrm{F}(4,40)=9.36, p<.05, \eta^{2}=.10$; duration: $\mathrm{F}(4,40)=3.79, p<.05, \eta^{2}=.03$; latency: $\mathrm{F}(4,40)=12.19$, $\left.p=.002, \eta^{2}=.16\right]$. Bonferroni-correct post-hoc comparisons revealed that upward vection was stronger than downward vection in the $26^{\circ} \mathrm{C}-27^{\circ} \mathrm{C}$ condition $(p<.05)$, and thus $\mathrm{H} 1$ was supported.

A second 3 (temperature) $\times 3$ (grating motion) repeated-measures ANOVA on the difference between perceived temperatures pre- and post-stimulus presentation revealed no significant main effect of temperature $\left[\mathrm{F}(2,20)=1.62, p=.22 ; \eta^{2}=.03\right]$ (see Figure 2). The main effect of grating motion was significant $\left[\mathrm{F}(2,20)=7.17, p=.0045, \eta^{2}=.08\right]$. Post-hoc tests (Holm's Sequentially Rejective Bonferroni Procedure) revealed significant differences between down and the other two conditions [up vs. down, $\mathrm{t}(10)=2.98, p=.04$; Cohen's $\mathrm{d}=.73$; down vs. static, $\mathrm{t}(10)=2.48, p=.03 ; \mathrm{d}=.31]$. There was also a trend towards significance between the up and static conditions, $\mathrm{t}(10)$ $=2.05, p=.06 ; \mathrm{d}=.29$. The interaction was significant $[\mathrm{F}(4,40)$ $\left.=2.64, p<.05, \eta^{2}=.12\right]$. Bonferroni-corrected post-hoc com- 

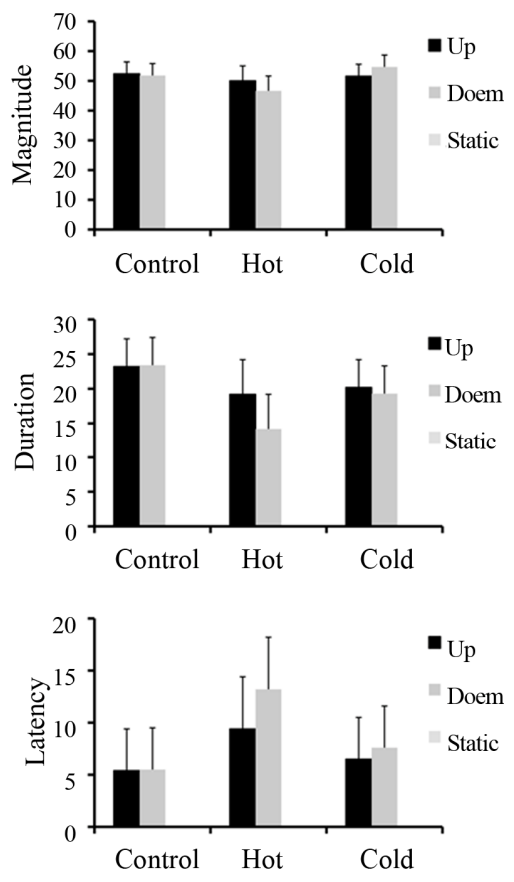

Figure 1.

Strength of vection. The unit of measurement for latency and duration were seconds, while magnitude was a rating from 0 to 100 . There was no vection in any static condition, and hence the "spaces" in the figures.

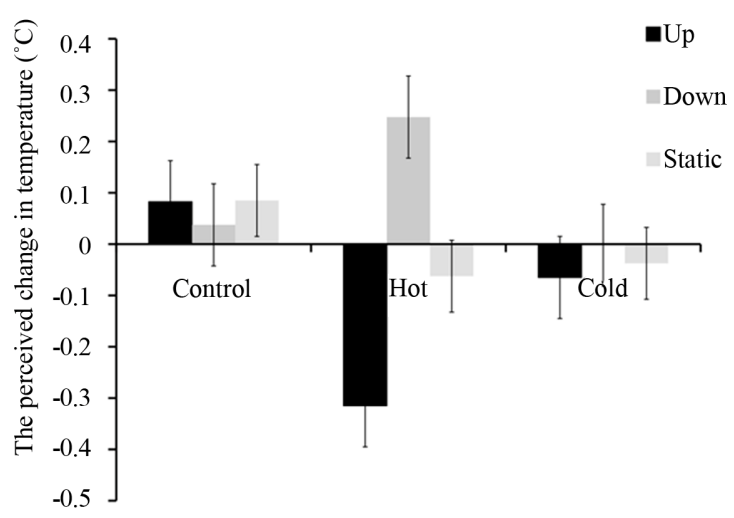

Figure 2.

The perceived change in temperature after vection.

parisons revealed that perceived room temperature was modulated by motion stimuli only in the $26^{\circ} \mathrm{C}-27^{\circ} \mathrm{C}$ condition $(p$ $<.05)$.

\section{Discussion}

Vection refers to the experience of illusory self-motion in response to large patterns of optic flow. The main issues explored in this study were whether (a) vection is influenced by changes in room temperature, and (b) perceived room temperature is changed by experiencing vection. Remarkably, the interaction between temperature and grating motion was significant, and thus vection seems to be influenced by room temperature. Further, and contrary to $\mathrm{H} 2$, upward vection produced a perceived drop in room temperature and downward vection resulted in a perceived rise, but only in the $26^{\circ} \mathrm{C}-27^{\circ} \mathrm{C}$ condition.

We speculate that, as upward vection was stronger than downward vection in the $26^{\circ} \mathrm{C}-27^{\circ} \mathrm{C}$ condition, there is a correspondence between heat and upward motion that exists in closed spaces, e.g. rooms and buildings where hot air rises. However, in the $5^{\circ} \mathrm{C}-6^{\circ} \mathrm{C}$ condition, downward vection was not significantly stronger than upward vection. It is somewhat surprising that an association exists only between $26-27^{\circ} \mathrm{C}$ and "up", and not between $5^{\circ} \mathrm{C}-6^{\circ} \mathrm{C}$ and "down". Although speculative, this unidirectional finding may be explained by the work of Riecke et al. (2008) who showed that the possibility of actual self-motion facilitates vection. In their experiment auditory circular vection was enhanced by suspending participants above the ground. In our experiment, participants' feet touched solid ground and they, presumably, knew that actual "downward" motion was impossible, whereas given the free space above each participant's head it was (theoretically) possible for them to move up into this free space.

To examine this hypothesis, we conducted an informal observation with 4 naïve volunteers in which their feet were kept off the ground, and thus upward and downward motion was (theoretically) possible; we, again, measured strength of vection. The results were similar to those of the main experiment, i.e. upward vection was stronger than downward vection in the $26^{\circ} \mathrm{C}-27^{\circ} \mathrm{C}$ condition. Thus, the idea that contact between one's feet and solid ground inhibits vection is not supported by our informal observations. That said, even though the participants' feet did not touch the ground, their buttocks did touch the chair. Further experiments are planned to determine whether manipulating the procedure shows correspondence effects in the other conditions. The current results suggest that illusory self-motion is stronger when there is a correspondence between two stimuli and one knows that physical motion is possible.

Contrary to $\mathrm{H} 2$, upward vection produced a perceived drop in room temperature while downward vection resulted in a perceived rise, but only in the $26^{\circ} \mathrm{C}-27^{\circ} \mathrm{C}$ condition. It is possible that participants were aware of the fact that hot air rises and, after experiencing illusory self-motion in the $26^{\circ} \mathrm{C}-27^{\circ} \mathrm{C}$ temperature condition, they expected an increase in room temperature. As the actual temperature remained constant after experiencing vection, because no physical positional change took place, there was a discrepancy between expected and actual room temperatures, which resulted in the room being judged colder than it actually was. However, given downward vection was weaker than upward vection in the $26^{\circ} \mathrm{C}-27^{\circ} \mathrm{C}$ and, here, downward vection resulted in a perceived increase in room temperature, this explanation is speculative. It might be that the hot temperature $\left(26^{\circ} \mathrm{C}-27^{\circ} \mathrm{C}\right)$ and vection stimuli used here contain some unknown features that correspond, whereas the cold temperature $\left(5^{\circ} \mathrm{C}-6^{\circ} \mathrm{C}\right)$ and vection stimuli did not. There is some evidence (see Pilcher, Nadler, \& Busch, 2002) that heat can be more attention-getting than can cold and, as such, it may be that a hotter room shifts attention to temperature, and thus participants became sensitive to it.

It is known that exposure to visual stimuli like those used here can create nausea in participants, and common autonomic reactions are cold sweating and reduced peripheral blood flow. These reactions are especially common among healthy, young people who do not suffer from vestibular disorders. These are natural autonomic responses and a shift in the autonomic nervous system towards a sympathetic reaction. Although each ex- 
perimental trial lasted only a short time, there were repeated exposures and the autonomic response is quick, especially if trials are repeated with short inter-trial intervals. That said, for autonomic responses to have been a confounding variable the reported influence of temperature on vection would have to be explainable having found that autonomic responses occurred in the $26^{\circ} \mathrm{C}-27^{\circ} \mathrm{C}$ temperature/downward motion (upward vection) condition but not in the $26^{\circ} \mathrm{C}-27^{\circ} \mathrm{C}$ temperature/upward motion (downward vection) condition, and that this increased the perceived strength of vection in the former condition. There is no evidence to support such a view.

In conclusion, we have demonstrated the existence of a new crossmodal correspondence, namely an association between temperature and directional up; vection modulated perceived temperature, and was modulated by actual temperature. As Parise and Spence (2012) argue, this correspondence might reflect the natural correlation between physical properties of the world, i.e. warmer air moves upwards relative to cooler air.

\section{Acknowledgements}

This work is supported by the Program to Disseminate Tenure Tracking System, MEXT, Japan.

\section{REFERENCES}

Cavanagh, P., MacLeod, D. I., \& Anstis, S. M. (1987). Equiluminance: Spatial and temporal factors and the contribution of blue-sensitive cones. The Journal of the Optical Society of America, 4, 1428-1438. http://dx.doi.org/10.1364/JOSAA.4.001428

Fischer, M. H., \& Kornmuller, A. E. (1930). Optokinetic ausgeloste Bewegungs-wahrnehmungen und optokinetinetisher Nystagmus. Journal of Comparative Neurology, 41, 273-308.

Fukuda, H., \& Seno, T. (2011). Shrinking neighbors: A quantitative examination of the 'Shrinking Building' illusion. Seeing Perceiving, 24, 541-544. http://dx.doi.org/10.1163/187847611X603756

Fukuda, H., \& Seno, T. (2012). Healin' groovy: Movement affects the appearance of the Healing Grid Illusion. Perception, 41, 243-246. http://dx.doi.org/10.1068/p7132

Marks, L. E. (2004). Cross-modal interaction in speeded classification. In G. Calvert, C. Spence, \& B. Stein (Eds.), The handbook of multisensory processes (pp. 85-105). Cambridge: MIT Press.

Martino, G., \& Marks, L. E. (2000). Cross-modal interaction between vision and touch: The role of synesthetic correspondence. Perception, 29, 745-754. http://dx.doi.org/10.1068/p2984

Miles, L. K., Karpinska, K., Lumsden, J., \& Macrae, C. N. (2010). The meandering mind: Vection and mental time travel. PLoS One, 5, e10825. http://dx.doi.org/10.1371/journal.pone.0010825

Palmisano, S., \& Chan, A. Y. (2004). Jitter and size effects on vection are immune to experimental instructions and demands. Perception, 33, 987-1000. http://dx.doi.org/10.1068/p5242

Parise, C. V., \& Spence, C. (2012). Audiovisual crossmodal correspondences and sound symbolism: A study using the Implicit Association
Test. Experimental Brain Research, 220, 319-333. http://dx.doi.org/10.1007/s00221-012-3140-6

Pilcher, J. J., Nadler, E., \& Busch, C. (2002). Effects of hot and cold temperature exposure on performance: A meta-analytic review. Ergonomics, 45, 682-698. http://dx.doi.org/10.1080/00140130210158419

Riecke, B. E., Schulte-Pelkum, J., Caniard, F., \& Bülthoff, H. H. (2005). Influence of auditory cues on the visually-induced self-motion illusion (circular vection) in virtual reality. In M. Slater (Ed.), Proceedings of the 8th International Workshop on Presence 2005 (pp. 49-57). London: University College London.

Riecke, B. E., Feuereissen, D., \& Rieser, J. J. (2008). Auditory self-motion illusions ("circular vection") can be facilitated by vibrations and the potential for actual motion. In S. N. Spence (Ed.), Proceedings of the 5th Symposium on Applied Perception in Graphics and Visualization 2008 (pp. 147-54). New York, NY: The Association for Computing Machinery.

Seno, T., Ito, H., \& Sunaga, S. (2009). The object and background hypothesis for vection. Vision Research, 49, 2973-2982. http://dx.doi.org/10.1016/j.visres.2009.09.017

Seno, T., Ito, H., Sunaga, S., \& Nakamura, S. (2010). Temporonasal motion projected on the nasal retina underlies expansion-contraction asymmetry in vection. Vision Research, 50, 1131-1139. http://dx.doi.org/10.1016/j.visres.2010.03.020

Seno, T., Ito, H., \& Sunaga, S. (2011a). Attentional load inhibits vection. Attention, Perception, \& Psychophysics, 73, 1467-1476. http://dx.doi.org/10.3758/s13414-011-0129-3

Seno, T., Ito, H., \& Sunaga, S. (2011b). Self-motion perception compresses time experienced in return travel. Perception, 40, 497-499. http://dx.doi.org/10.1068/p6885

Seno, T., Ito, H., Sunaga, S., Hasuo, E., Nakajima, Y., \& Ogawa, M. (2011). Consistency between modalities enhances visually induced self-motion (vection). In G. Suzuki (Ed.), Proceedings of the 12th International Multisensory Research Forum. Fukuoka: I-Perception.

Seno, T., Ogawa, M., Ito, H., \& Sunaga, S. (2011). Consistent air flow to the face facilitates vection. Perception, 40, 1237-1240. http://dx.doi.org/10.1068/p7055

Seno, T., Taya, S., Ito, H., \& Sunaga, S. (2011). Mental number line in depth revealed by vection. Perception, 40, 1241-1244. http://dx.doi.org/10.1068/p6965

Seno, T., Yamada, Y., \& Ihaya, K. (2011). Narcissistic people cannot be moved easily by visual stimulation. Perception, 40, 1390-1392. http://dx.doi.org/10.1068/p7062

Seno, T., \& Fukuda, H. (2012). Stimulus meanings alter illusory selfmotion (vection): Experimental examination of the train illusion. Seeing \& Perceiving, 25, 631-645. http://dx.doi.org/10.1163/18784763-00002394

Soto-Faraco, S., Spence, C., \& Kingstone, A. (2004). Cross-modal dynamic capture: Congruency effects in the perception of motion across sensory modalities. The Journal of Experimental Psychology: Human Perception and Performance, 30, 330-345. http://dx.doi.org/10.1037/0096-1523.30.2.330

Williams, L. E., \& Bargh, J. A. (2008). Experiencing physical warmth promotes interpersonal warmth. Science, 322, 606-607. http://dx.doi.org/10.1126/science.1162548 